\title{
Cidades a contrapelo: por outras possibilidades de urbano
}

\section{Counter cities: Urban Possibilities}

\author{
Carolina de Castro Anselmo \\ Universidade de Coimbra, Coimbra / Portugal \\ ccanselmo@gmail.com
}

Resumo: O pensamento de Walter Benjamin e Boaventura de Souza Santos parecem se aproximar, apesar do anacronismo de suas escritas, pelas visibilidades e invisibilidades que o saber moderno racional construiu. Propomos refletir então, a partir da aproximação de ambos pensadores, sobre uma das invisibilidades urbanas pouco exploradas pelas teorias hegemônicas: a relação dos quilombos com as transformações das cidades brasileiras, tendo o Quilombo das Mangueiras situado em Belo Horizonte, como caso de análise. Parece nos urgente perceber, ecoar e contribuir com outras maneiras de ver, estar, pensar e construir o urbano. E também de encontrar potenciais para a resistência e luta nas cidades.

Palavras-chave: exclusão abissal; urbano; contrapelo.

Abstract: The thought of Walter Benjamin and Boaventura de Souza Santos seems to be approaching, despite the anachronism of their writings, that reflect the visibilities and invisibilities that the modern rational knowledge has built. We propose, therefore, to reflect on one of the urban invisibles that is less explored by the hegemonic theories: the relation of the quilombos with the transformations of the Brazilian cities, using the Quilombo Mangueiras, which is located in Belo Horizonte, as a case of analysis. It seems urgent to perceive, echo and contribute with another point of view, and another way of living, thinking and building the urban. It's also important to find out potentials for resistance and struggle in the cities.

Keywords: exclusion; urban; history.

Recebido em: 30 de outubro de 2017.

Aprovado em: 6 de fevereiro de 2018. 


\section{Notas preliminares}

Não é raro nos depararmos com a ideia de que os acontecimentos passados determinam as configurações do mundo presente. Quando falamos de cidades, essa lógica não é diferente. Estudamos os aglomerados urbanos de diferentes épocas, suas conformações sociais, políticas, econômicas e transformações espaciais relacionadas. Entendemos como o encadeamento dos fatos e a construção e manutenção de memórias podem configurar as realidades urbanas atuais.

Ao longo do século XX, o ritmo das transformações urbanas se acentuou e marcou não só a paisagem como também as relações. Alteraram-se significativamente os modos de estar, pensar, ver, apreender e fazer cidades. De maneira geral, muitas das questões urbanas que hoje são foco de análise e reflexão estão associadas a fatos originados ou relacionados às mudanças decorrentes do desenvolvimento industrial. Dentre elas apontamos o rápido crescimento e adensamento, a falta de acesso às infraestruturas para todos que resultaram em problemas de saúde, de falta de trabalho, de moradias, um crescente movimento da tentativa de controle, dominação e exploração da natureza. ${ }^{1}$ Por outro lado, as cidades foram tidas como lugar de livre afirmação dos sujeitos possível pelo anonimato na multidão, da emancipação, dos encontros inesperados e entre diferentes. ${ }^{2}$ A cidade foi tida como o lugar do progresso.

Olhando para o mundo hoje, reconhecemos que as cidades, em suas mais diferentes escalas, não são lugares livres das disputas, explorações, opressões e pobrezas. Antes pelo contrário. As relações urbanas são mais complexas e contraditórias e ganharam dimensões não imaginadas, influenciadas ainda pelo processo de globalização financeira e monopolização do poder.

Podemos observar no desenvolvimento urbano de muitas cidades situações que mantém e reproduzem constantemente situações de exclusões e injustiças. Em Belo Horizonte são muitos os conflitos urbanos que podem ser apontados nesse sentido. As disputas pelos territórios do

\footnotetext{
${ }^{1}$ Explicita-se com essa colocação um entendimento moderno que entende a natureza como algo separado e externo à cultura.

${ }^{2}$ George Simmel (1997) reatualiza o aforismo medieval "os ares da cidade libertam" e desenvolve uma reflexão sobre a condição moderna da metrópole do início do século $\mathrm{XX}$.
} 
Quilombo Mangueiras, que está situado a norte da cidade, no limite com Santa Luzia, pode ser citado como um exemplo desses processos. Embora estudos antropológicos feitos pela Universidade Federal de Minas Gerais reconheçam que há mais de 150 anos o território esteja ocupado pelos descendentes do casal de lavradores afrodescendente Cassiano e Vicência, a propriedade pertence à família Werneck desde a década de 1920 (NÚCLEO DE ESTUDOS DE POPULAÇÕES QUILOMBOLAS E TRADICIONAIS/ UFMG, 2014). Existem contestações sobre tal posse que questionam não só o processo de compra ou tomada do terreno pela influente família, como também acusam o fato de terem desconsiderado a presença centenária, e anterior a fundação da cidade, da comunidade quilombola.

Revela-se aqui um antigo e recorrente fenômeno de invisibilização dos quilombos nos processos de urbanização. Não há registros sobre sua existência na história oficial da cidade, além das violentas ocupações e reduções do território quilombola original que ao longo dos anos aconteceram por diferentes motivos.

Cientes de tais fatos, parece-nos pertinente levantar algumas questões a serem consideradas na apreensão dos contextos urbanos e nas suas produções atuais: como construímos nosso modo de ver e compreender as cidades? Questionar e desconfiar das histórias e narrativas oficiais, bem como dos modelos urbanos hegemônicos influenciados por forças globais poderiam nos levar a outras condições urbanas, com menos desigualdades, opressões, destruições? Quais são cidades invisíveis (MENDIETA, 2001; CALVINO, 2003) não estamos vendo? Elas poderiam nos abrir outras possibilidades urbanas?

A noção de visibilidade e invisibilidade é trabalhada, em diferentes campos, por alguns autores e nos parece ser uma chave de aproximação de falas e fatos de tempos distintos. Tencionar a ordem do visível e invisível, das fronteiras de tempo e espaço, talvez possa nos abrir caminhos para pensar, praticar e construir melhores condições de vida urbana hoje. Nesse sentido propomos um diálogo entre Walter Benjamin, que observou as transformações sócio-espaciais e suas formas de dominação e exclusão no início do século XX e Boaventura de Souza Santos que aponta para alguns fenômenos semelhantes atualmente. 


\section{Do estado de exceção permanente à exclusão abissal}

As transformações da cidade moderna industrial do final do século XIX e início do século XX vieram acompanhadas de um caráter ordenador e definidor dos espaços. Com a justificativa de resolver os problemas sanitários decorrentes do rápido adensamento das cidades industriais, mas também de atender às novas exigências e velocidades de circulação de mercadorias e trabalhadores, os princípios racionalistas e formalmente rígidos direcionaram as intervenções, reformas e remodelações propostas por planos como o de Haussmann em Paris. Uma imagem de cidade homogênea e asséptica começava a ser construída para se adequar às promessas do progresso e desenvolvimento que se anunciava.

É nesse contexto que Walter Benjamin observou como o rítmo da produção, da circulação de mercadorias e do capital passaram a definir não só os espaços, como a temporalidade da vida social (1985a, 1987b, 2006c). Temporalidade fundamental para um sistema produtivo que exigia a mensuração do trabalho para determinar os valores de troca das mercadorias. Já não mais importava o caráter qualitativo e fluido do tempo, mas sim, o quantitativo e preciso. Trabalho e tempo tornamse mercadorias que estão submetidas a um processo de racionalização, controle e dominação da natureza. O tempo capitalizado, instituído pelo processo de industrialização, estava associado a um caminho sem volta de uma história evolutiva que levaria a um destino já desenhado, desenvolvido e glorioso. Nesse sentido, o tempo se torna homogêneo e se coloca como irreversível. Desse contexto surgem os questionamentos e críticas benjaminianas em relação à história linear, mecânica, homogênia, cegamente otimista e aliada à ideologia do progresso (BENJAMIN, 1985a, 2006c).

Tais questões podem ser observadas em suas teses apresentadas no texto Sobre o Conceito da história, escrito em 1940:

Há um quadro de Klee que se chama Angelus Novus. Representa um anjo que parece querer afastar-se de algo que ele encara fixamente. Seus olhos estão escancarados, sua boca dilatada, suas asas abertas. O anjo da história deve ter esse aspecto. Seu rosto está dirigido para o passado. Onde nós vemos uma cadeia de acontecimentos, ele vê uma catástrofe única, que acumula incansavelmente ruína sobre ruína e as dispersa a nossos pés. Ele gostaria de 
deter-se para acordar os mortos e juntar os fragmentos. Mas uma tempestade sopra do paraíso e prende-se em suas asas com tanta força que ele não pode mais fechá-las. Essa tempestade o impele irresistivelmente para o futuro, ao qual ele vira as costas, enquanto o amontoado de ruínas cresce até o céu. Essa tempestade é o que chamamos progresso. (BENJAMIN, 1985a, p. 226)

O anjo de rosto assustado, voltado para o passado, não consegue se manter parado. É puxado por uma força irremediável que lhe lança para o futuro. Segue então em seu movimento, adiante e de marcha ré, rumo a um tempo futuro obscuro e incerto. Se o passado se mostrava como um acúmulo de ruínas e de fracassos, o futuro que ele não vê seria provavelmente uma catástrofe. $\mathrm{O}$ autor revela aqui sua desconfiança em relação às transformações temporais, espaciais, sociais e econômicas pautadas na lógica racional industrial as quais as cidades do final do século XIX e XX estavam sendo submetidas. Contrariando a noção de história como um processo de evolução, via o decorrer do tempo como um constante processo de destruição. ${ }^{3}$

Contrapondo-se às aspirações da marcha em direção ao futuro desenvolvido, Benjamin observa que a história não é uma evolução tão positiva e otimista como era colocado pelas narrativas dominantes, no caso, a burguesa do progresso. Estas se construíram por uma lógica cartesiana e são sempre contadas a partir da perspectiva hegemônica dos vencedores. ${ }^{4}$ Afirmam valores que contribuem para a manutenção de um sistema de poder e opressão e ainda se fortalece pelo empobrecimento das experiências ${ }^{5}$ que se tornam cada vez mais homogêneas, uma vez que a racionalidade passa a organiza as relações sociais, o tempo, o trabalho e os espaços. As experiências deixam de ser transmitidas e

\footnotetext{
${ }^{3}$ Benjamin coloca que todas as coisas estão sujeitas ao caráter destrutivo (BENJAMIN, 1987b). De acordo com o autor, esse caráter destrutivo a tudo arruína e pode elimina até mesmo os vestígios. Desta maneira, simplifica o mundo colocando a destruição como sua vocação.

4 "O vencedor de hoje é o capitalismo em sua fase mais recente de globalização. Esse sistema econômico sempre necessita se expandir a fim de existir; a fim de expandir, teve de limpar o que passou antes. Em suma, a fim de ser, é necessário esquecer. Benjamin expõe assim: a tempestade "que chamamos de progresso" se move a partir do esquecimento." (WOHFARTH, in SEDLEMAYER; GINZBURG, 2012, p. 222) ${ }^{5}$ Ver: BENJAMIN (1985a, p.114-119).
} 
construídas coletivamente em tempos compartilhados para se construírem por experiências individuais, solitárias e cada vez mais massificadas e empobrecidas. Irving Wohlfarth escreve que

A modernidade, como Benjamin descreve, é marcada pelo desaparecimento ou deteriorização de traços de memória, aura, experiência, narração de histórias, hábitos (Gewohnheit), o ato de habitar (Wohnem) etc. $\mathrm{O}$ apagamento de traços seria, assim, um imperativo histórico-mundial em curso, incorporado ao modo de produção capitalista (e, hoje devemos acrescentar, a todos os empreendimentos coloniais e genocidas). (WOHFARTH, in SEDLEMAYER; GINZBURG, 2012, p. 204)

Boaventura de Souza Santos (2008b), entende que o empobrecimento da experiência é decorrente da razão metonímica, que seria aquela assente na ideia de totalidade colocada como única forma de racionalidade. ${ }^{6}$ É uma razão seletiva, silenciadora e redutora, uma vez que exclui as multiplicidades de formas de estar e relacionar no mundo. Consequentemente, interfere nas subjetivações e posicionamentos críticos que poderiam contestar a ordem estabelecida, fazendo das construções históricas processos hegemônicos e homogêneos.

Nessa perspectiva, a história poderia ser compreendida como uma cadeia de acontecimentos [grifos do autor] lineares e é exatamente esse ponto que Benjamin critica. Quando a história é contada a partir de um ponto de vista dominante, sem quaisquer desvios ou rupturas que pudessem desestabilizar o sistema, passa a ser um instrumento de poder e dominação. O que faz dela um algo que produziu, reproduziu e, no nosso entendimento, continua reproduzindo, realidades opressoras e de exploração. Segundo Benjamin, "[n]unca houve um monumento da cultura que não fosse também um monumento da barbárie. E, assim como a cultura não é isenta de barbárie, não o é, tampouco, o processo de transmissão da cultura. (BENJAMIN, 1985a, p. 225)".

\footnotetext{
${ }^{6}$ No texto Para uma sociologia das ausências e uma sociologia das emergências, o autor assume que existe uma razão indolente, que é ocidental e dominante, e não é capaz de reconhecer e considerar importante a variedade de experiências sociais do muno. A razão indolente pode ser reconhecida sob quatro formas distintas: razão impotente, razão arrogante, razão metonímica e razão proléptica. no texto (SANTOS, 2008b, p.1-4)
} 
Conhecer a história oficial não implica, portanto, conhecer o passado como ele de fato aconteceu (BENJAMIN, 1985a). Significa apenas conhecer como foi registrado, as vezes como estratégia das classes dominantes para manter uma tradição. A memória é uma decisão da classe dominante e sua hegemonia produz o esquecimento dos oprimidos (WOHFARTH, in SEDLEMAYER, GINZBURG, 2012, p.222). Benjamin entende que "a tradição dos oprimidos nos ensina que o estado de exceção em que vivemos é na verdade a regra geral" (BENJAMIN, 1985a, p.226).

Ao observarmos as realidades urbanas hoje, reconhecemos diversas situações que poderiam ilustrar a discussão acima, o que evidencia a emergência em questionar a posição dos saberes modernos que tendem a uniformizar os parâmetros interpretativos e por isso são violentos. Inferiorizam, ocultam, apagam e invisibilisam outras formas de estar no mundo que sejam distintas das dominantes. ${ }^{7}$

$\mathrm{O}$ autor português entende que o pensamento moderno ocidental é um pensamento abissal que segue contribuindo para manutenção dos poderes hegemônicos (SANTOS, 2007a). É um pensamento que se constrói por um sistema de distinções que separa ${ }^{8}$ duas realidades: uma visível e outra invisível. O lado visível é reconhecido como hegemônico e chamado de metropolitano. O invisível, relativo às realidades subalternizadas, seria denominado por colonial. O olhar metropolitano não vê e não reconhece o que está do lado colonial produzindo assim a sua inexistência. Uma vez inexistente, não há como apreender, incluir, ou transformar uma realidade. Ou seja, criam-se ausências e as exclusões tornam-se radicais e abissais.

A humanidade moderna não se concebe sem uma subumanidade moderna. A negação de uma parte da humanidade é sacrificial, na medida em que constitui condições para que a outra parte da humanidade se afirme como universal." (SANTOS, 2007a, p.76)

\footnotetext{
${ }^{7}$ Santos exemplifica tal situação ao escrever "[o] olhar que vê uma pessoa cultivar a terra com uma enxada não consegue ver nela senão o camponês pré-moderno" (SANTOS, 2008b, p.10). Reconhecemos aqui que olhar que inferioriza, não valoriza ou não enxerga algo por estar fora da razão que estipula e determina os valores contemporâneos dominantes.

${ }^{8}$ Tal separação é feita por uma linha abstrata denominada pelo autor de linha abissal.
} 
Se tomarmos a ideia do pensamento benjaminiano que vê a modernidade como um período de destruições, onde os vestígios e os traços de memórias são apagados, onde há o apagamento do apagamento, ${ }^{9}$ entenderemos porque o autor alemão vê a história da barbárie como reprodutora de barbárie. O pensamento abissal também se auto reproduz. Como é um saber monocultural, não vê outras perspectivas, outras marchas, sendo a reprodução do sistema a única possibilidade.

Podemos observar tais reproduções e manutenção desse sistema excludente e opressor, produtores de ausências e invisibilidades nos contextos urbanos. Sabemos que o processo de construção social e espacial das cidades e de sua reflexão teórica não contemplaram grupos entendidos como subalternizados. A não ser reforçando sua imagem de inferiorização colocando-a como algo natural, contribuindo para sua imobilidade e permanência nesse lugar invisível, inexistente.

Quando estudamos a formação das cidades brasileiras, nos deparamos com processos excludentes e opressores semelhantes aos da cidade industrial vista por Benjamin, motivados talvez pela mesma racionalidade moderna e ocidental que também produziu ausências e exclusões abissais. Ainda temos um histórico de colonização que disputou outras desigualdades, segregações e opressões como por exemplo, a escravidão. Anibal Quijano (2000) cunhou o termo colonialidade do poder, ao reconhecer que existe uma forma de poder que seguiu sendo reproduzida no contexto colonial, mesmo após a independência. Podemos reconhecê-la hoje nas lutas que urbanas que ganham outras leituras para além das diferenças de classes. Vemos hoje que as injustiças, exclusões e opressões passam também por outros vieses, sendo o racial muito evidente e ligado a luta quilombola.

Frente à esses fatos, Santos (2007a) coloca a necessidade de encontrar saídas que passam por elaborar um pensamento alternativo de alternativas. Propõe abandonar a concepção linear do tempo e dessa forma criar condições para que seja possível uma co-presença radical. Propõe uma ecologia de saberes que reconheça e se construa por uma

\footnotetext{
9 "Na reflexão de Benjamin, o estatuto paradoxal do rastro remete à questão da manutenção ou do apagamento do passado, isto é, à vontade de deixar marcas, até monumentos de uma existência humana fugidia, de um lado, e às estratégias de conservação ou de aniquilamento do passado, do outro." (GAGNEBIN, in SEDLEMAYER; GINZBURG; 2012, p. 27)
} 
pluralidade de conhecimentos heterogêneos que operam em diferentes contextos, por diferentes práticas que não centram-se nem se constroem pelos conhecimentos ocidentais e pela razão metonímica.

Encontra-se outra aproximação a Benjamin quando essa fala da necessidade de "escovar a história a contrapelo" e construir outra concepção de história, de tempo. Estabelecer assim, outra relação com o passado que considere as tradições dos vencidos e oprimidos, quebrando a continuidade hegemônica e abrindo outras possibilidades.

Como esse contrapelo poderia então ser pensado no contexto das cidades? Poderíamos abrir espaço para que outras teorias e práticas urbanas emerjam e coexistam, a partir de outras histórias, relações e espaços que foram ocultadas das reflexões e práticas oficiais? Em que esse deslocamento ou abertura poderia contribuir?

Propomos então, um exercício inicial nesse sentido. Começamos com uma inversão cronológica. Ao invés de voltar ao passado para apreender o presente, olhemos para as perspectivas futuras..$^{10}$ Diferentemente do Anjo da história, propomos olhar para frente para ver atrás. E, quem sabe encontrar outros modos de ver, para desocultar passados que possam nos abrir outras possibilidades de futuros.

\section{Escovar a contrapelo}

Quando nos colocamos frente aos desafios das cidades contemporâneas excessivas, com lógicas globais, altos índices de pobreza, condições subhumanas de vida, grandes impactos e destruição ambientais que comprometem nossa sobrevivência, nos vemos limitados diante de novos desafios. ${ }^{11}$

Os modos de vida urbanos capitalistas pautados na exploração de recursos naturais se mostram insustentáveis e o planeta já anuncia seu esgotamento. Já não são poucas as evidências da crise hídrica, do aquecimento global, das extinções de diferentes espécies. Ao

\footnotetext{
${ }^{10}$ Lefebvre também sugere uma inversão do tempo linear histórico quando elabora seu pensamento sobre o método regressivo-progressivo que seria um duplo movimento, de ir "do virtual ao atual, do atual ao passado" e "do superado e do finito [grifo do autor] ao movimento que declara seu fim [grifo do autor], que anuncia e faz nascer algo novo". O futuro ilumina o passado, o virtual permite examinar e situar o realizado. (LEFEBVRE, 1999, p. 33)

${ }^{11}$ Ver United Nations, 2013.
} 
considerarmos a estimativa de um crescimento significativo das áreas urbanas, principalmente em países pobres do Sul Global que ainda não tem acesso a muitos dos "produtos" e modos de consumos que a cidade oferece, vemos a impossibilidade de sobrevivermos seguindo esses padrões. Evidencia-se a urgência de encontrarmos alternativas ao modelo urbano que visa sempre o desenvolvimento. Mesmo que esse seja sustentável, ainda traz consigo a ideia de desenvolvimento que parece incoerente com as condições que o planeta apresenta. ${ }^{12}$

$\mathrm{Na}$ tentativa de mudar o rumo dessa marcha, que continua tendo o desenvolvimento e o progresso como motor das transformações, seria possível propor uma alternativa à lógica urbana dominante? Realidades invisibilisadas na história poderiam contribuir na construção de outras cidades, outras histórias e outros futuros?

Tais questionamentos nos trazem a possibilidade de aproximação às táticas ${ }^{13}$ encontradas pela população afrodescendente no Brasil, em sua organização nos quilombos. Olhemos para essa história não com o foco na violência da escravidão, como é recorrente, e sim no potencial insurgente que as relações sociais e espaciais que se moldaram podem revelar. Olhemos para os processos de resistência, para as criatividades desenvolvidas, para as outras racionalidades que foram capazes de sobreviver em meio às pressões dominantes, aos caráteres destrutivos, as racionalidades hegemônicas.

Quem sabe, possa ser possível, a partir desses conhecimentos, repensar os contextos e planejamentos urbanos com intuito de contribuir na inversão da marcha catastrófica da história das cidades vista por Benjamin e também por outros autores.

Voltamos então ao Quilombo Mangueiras situada em Belo Horizonte. A comunidade tem seu território dentro de uma área de preservação ambiental que possui muitas nascentes, água corrente e

\footnotetext{
${ }^{12}$ Apesar dos muitos estudos sobre as cidades, grande parte das reflexões centraramse em realidades euroamericanas com conformações demográficas muito distintas das novas metrópoles que surgem e se afirmam como novos epicentros urbanos (PARNELL; OLDFIELD, 2014). Evidencia-se também a incapacidade do conhecimento social e político acumulado para dar respostas e encontrar solução para a realidade descrita acima (FORTUNA, 2002).

${ }^{13}$ Segundo De Certeu (1994), apresenta seu conceito de tática como uma maneira criativa de desviar daquilo que foi imposto, uma maneira de utilizar a ordem estipulada para o lugar.
} 
diversidade de fauna e flora que convivem em harmonia com os membros da comunidade.

Entretanto, a área não está livre de danos ambientais e poluições pela proximidade com áreas já urbanizadas e adensadas da cidade. Ainda assim, é uma das últimas áreas livres verdes de Belo Horizonte e isso imbrica a ela maior relevância ambiental.

Recentemente a preservação ambiental da área e o cotidiano do quilombo foram ameaçados pelos interesses imobiliários, que moldam a cidade com seus padrões dominantes baseados nos interesses de mercado. A área, conhecida por Mata do Isidoro ou Granja Werneck sofreu uma valorização decorrente das operações urbanas que permitiam um maior coeficiente construtivo, a construção da Cidade Administrativa do Estado de Minas Gerais e ampliação do Aeroporto Internacional Tancredo Neves, em Confins. A área que até então era tida como uma das mais pobres da cidade, passou a ser disputada e foco de interesse de imobiliárias que pretendiam construir no terreno um megaempreendimento que contava com 72 mil apartamentos, shopping center, hipermercado, escolas, postos de saúde, entre outras estruturas.

Caso o empreendimento fosse implantado os impactos seriam enormes. Além de influenciar os modos de vida da comunidade, que dependem da terra e reconhecem forte simbolismo nos elementos naturais, uma das poucas livres e remanescentes da cidade ficaria comprometida.

Entendemos, portanto, que urbanizar essa área da forma como foi proposto, seguindo modelos de urbanização dominantes pautados na lógica de mercado, seria um processo violento que contribuiria para seguirmos rumos às catástrofes ambientais previstas para o futuro insustentável.

Em contrapartida, o modo de vida quilombola parece mais integrado com a natureza e menos predatório. A presença do quilombo na área e seu ainda inicial processo de desocultamento e desinvibilisação fortaleceram a luta e resistência contra a implantação do empreendimento. Em 2016 a comunidade teve a posse da terra reconhecida, após anos de luta, o que contribuirá para manutenção da área verde, embora não seja ainda uma garantia. Ao longo dos anos muita área já foi subtraída do perímetro entendido como original quilombola.

Desolcultar os quilombos, perceber a potência do seu caráter de resistência à ordem dominante que é notado desde sua origem e seus modos de vida mais integrados com a natureza, construídos a partir de outros saberes, pode nos ajudar construir outras formas de urbano. 
Os quilombos, ${ }^{14}$ ou mocambos como denominado pelos próprios afrodescendentes surgiram no Brasil com o início do tráfico negreiro, formados por aqueles que fugiam da sua condição de explorados como escravos. Desde o início se construíram como lugares de resistência à ordem imperial dominante. Tinham como característica um difícil acesso e isso acabou por lhes conferir um isolamento social que contribuiu para a construção de uma rede de solidariedade que, segundo Adrelino Campos (2005), foi um forte elemento de estratégia de guerra.

Eram lugares possíveis de sobrevivência que apresentavam possibilidade de autonomia ao sistema que oprimia e explorava tal população. Outras lógicas, distintas da hegemônica que se consolidava com o desenvolvimento tecnicista nas cidades, se construíam. A noção de território, territorialidade, identidade espacial, por exemplo, dependia de outro entendimento da relação tempo/espaço.

Como os mocambos eram moventes no período da escravidão, se deslocavam quando eram descobertos e reconfiguravam em outros locais, a ideia de território acabou por se desenhar pelo campo de força e pela teia de relações sociais que determinavam limites e diferenças entre o grupo quilombola e os outros. A territorialidade dizia respeito à relação entre o indivíduo e o lugar apropriado. A identidade era construída pelo grupo, dentro do espírito da rede de solidariedade, e também pela forte ligação com o meio ecológico, com a infra-estrutura e com os membros da comunidade (CAMPOS, 2005). Mais do que um território físico, os quilombos eram territórios simbólicos.

Essa lógica do movimento servia não só como resistência ao sistema escravagista como também participou da história e expansão das cidades. Quando descobertos, em áreas próximas às cidades, se deslocavam e o local abandonado era incorporado ao tecido urbano sendo ocupado por outras atividades. Após a abolição da escravatura, os quilombos seguiram recebendo não só negros que não tinham condições de inserção na vida social e econômica, como também pessoas de outras origens, branca ou indígena, que pela condição marginal e de pobreza, também não se inseriam nos contextos formais urbanos.

Muito se fala de ocupações irregulares que originaram as favelas, mas muito pouco se fala dos quilombos urbanos que também fazem

\footnotetext{
${ }^{14} \mathrm{O}$ termo quilombo tem origem em Angola e significava acampamento de guerreiros na floresta, Administrado por chefes rituais de guerra. (RATTS, 2006, p. 58)
} 
parte da história das cidades. Hoje eles seguem presentes sendo que alguns se mantêm com autonomia, outros nem tanto. Muitos ainda são estigmatizados e encontram-se em situação marginalizada.

O fato é que os desvios encontrados por esse grupo para sobrevivência dentro do sistema que os oprimia, através das relações sociais, espaciais e com a natureza, permitiram que muitas pessoas vivessem em situação digna e muito melhor do que a de muitos pobres sujeitos às misérias e condições sub-humana que as cidades visíveis propiciavam. Um estudo mais aprofundado a esse respeito merece ser feito e pode ser revelador para reconfigurar a história dos quilombos na cidade, como também podem apontar caminhos para lidar os problemas urbanos atuais.

Ainda hoje, muitas comunidades estruturam a vida de forma semelhante a essas comunidades. Muitas delas mantem uma relação respeitosa com a natureza porque reconhecem seu importante papel para sua sobrevivência, seja pelo fornecimento de alimento ou por outras necessidades cotidianas, como por exemplo, lazer ou simbolismo religioso. Os quilombos, mais do que se apresentarem como lugares marginais ou subversivos, podem nos fornece alternativas de modos de vida que são passíveis de existirem simultaneamente a outros modos de vida. Podem nos oferecer outro modo de ver, de estar e de fazer cidades que o pensamento moderno ocidental e as narrativas dominantes apagaram das nossas histórias como possibilidades.

Podemos considerar a hipótese de muitas dessas lógicas serem incorporadas às áreas das cidades não só como forma resistências de grupos subalternizados, mas também como possibilidade de maior equilíbrio ambiental e estratégias para muitas pessoas conseguirem existir na cidade e alcançarem uma condição de vida digna. Também podem ser alternativas provocadoras às ordens dominantes que tentam moldar os espaços seguindo sempre um mesmo padrão de modos de vida hegemônicos.

Algumas resistências e desvios urbanos vêm demonstrando um movimento de organização nesse sentido tático. Redes de solidariedades estão sendo construídas, possibilidades de geração autônoma de recursos através de conhecimentos da agroecologia vem sendo utilizado. Uma consciência sobre o cuidado com as áreas ambientais vem sendo desenvolvida e usada como forma de preservação e de negociação para permanência de grupos em certos territórios. Um entendimento de uma 
lógica sistêmica de vida, onde problemas viram soluções, sem que seja preciso fazer grandes investimentos e impactos ambientais parece emergir em algumas áreas urbanas periféricas. Talvez possamos reconhecer nesses casos alguma aproximação aos modos de vida quilombolas. Talvez esse reconhecimento seja uma possibilidade de deslocamento da posição de exclusão abissal para um lugar, de fala e exemplo, capaz de dar melhores respostas à presente crise ambiental, social e urbana. Ou mesmo como forma de subversão à história oficial, mostrando que mundos diversos são possíveis de coexistirem respeitando suas diferenças.

\section{Considerações finais}

Essa é apenas uma primeira aproximação ao tema. Mais do que apresentar respostas, pretendeu-se fazer aqui provocações e disputar reflexões sobre a questão urbana. As guerras e as disputas de poder seguem presentes nas cidades, mas talvez nunca tenha sido tão urgente escovar a história a contrapelo dada a emergência colocada pelas previsões de futuro para o planeta que comprometem nossa sobrevivência. Embora se reconheça que as forças globais sejam complexas e poderosas, exigindo grandes reconfigurações e esforços para reais transformações de mundo, reconhece-se também a incapacidade de elaborar grandes modelos totalitários para os aglomerados urbanos visando tais mudanças. Ainda de acordo com Boaventura,

[m]uitas das experiências subalternas de resistência são locais ou foram localizadas e assim tornadas irrelevantes ou inexistentes pelo conhecimento abissal moderno, o único capaz de gerar experiências globais" (SANTOS, 2007a, p. 79)

As táticas baseadas nas experiências dos mocambos apresentadas atuam numa escala micropolítica e são limitadas frente às forças globais. Por outro lado, impulsionam reinvenções, desvios, que muitas vezes não interessam às forças dominantes e, por isso, não ganham a atenção devida para enfrentar as disputas e guerras urbanas. Microutopias que motivem pequenos movimentos talvez possam provocar e motivar transformações. Talvez possam ser essas abordagens fragmentadas, as alternativas para intervir no curso das megacidades. 
Apesar das cidades hoje apresentarem características muito distintas da cidade industrial observada por Benjamin, vemos que seu pensamento segue sendo atual para lidar com as barbáries, com as lutas e disputas que acontecem nos contextos urbanos e com as perspectivas catastróficas de futuro que ainda se colocam diante de nós. Apesar de serem necessários deslocamentos epistemológicos, o conhecimento acumulado pelas diferentes lentes sobre a cidade é válido e nos permitem fazer perguntas. O importante é pensar agora em novos caminhos, em outras maneiras de ver, em co-existências possíveis, capazes de dar melhores respostas aos desafios que se apresentam diante de nós. Escovar a história a contrapelo segue sendo uma necessidade e uma provocação para contrariar a história dominante que alimenta o estado de exceção ainda permanente e abissal.

\section{Referências}

ASSESSORIA DE COMUNICAÇÃO. Quilombolas comemoram melhorias na nascente do Mangueiras. Projeto Manuelzão UFMG. 2017, Abril, 12. Disponível em: <http://www.manuelzao.ufmg.br/ comunicacao/noticias/quilombolas-comemoram-melhorias-na-nascentedo-mangueiras $>$. Acesso em: 1 fev. 2017.

BENJAMIN, Walter. Experiência e Pobreza. Magia e técnica, arte e política: ensaios sobre literatura e história da cultura. São Paulo: Brasiliense, 1985a.

BENJAMIN, Walter. Rua de mão única. In: . Obras escolhidas volume 2. São Paulo: Brasiliense. 1987b.

BENJAMIN, Walter. Teoria do conhecimento, teoria do progresso. In: . Passagens. Belo Horizonte: Editora UFMG; São Paulo: Imprensa Oficial do Estado de São Paulo, 2006c.

CALVINO, Ítalo. As cidades invisíveis. 2. ed. São Paulo: Companhia das Letras, 2003.

CAMPOS, Andrelino. Do Quilombo à Favela: a produção do "espaço criminalizado" no Rio de Janeiro. Rio de Janeiro: Bertrand Brasil, 2005.

CERTEAU, Michael de. A invenção do cotidiano: artes de fazer. Petrópolis: Vozes, 1994. 
FORTUNA, Carlos (Org.). Cidade, cultura e globalização: ensaios de sociologia. 275. ed. Oeiras: Celta Editora, 1997.

GOMES, Maíra. Em Minas Gerais, empreendimento coloca quilombo em risco. Brasil de Fato: uma visão popular do Brasil e do mundo. 21 mar. 2014. Disponível em: <https://www.brasildefato.com.br/node/27846/>. Acesso em: 1 fev. 2017.

LOWY, Michael. A filosofia da história de Walter Benjamin. Estud. av. [online, v. 16, n. 45, p.199-206, 2002. Disponível em: <http://www.scielo. br/scielo.php?script=sci_arttext\&pid=S0103-40142002000200013 $>$. Acesso em: 30 out. 2017.

NÚCLEO DE ESTUDOS DE POPULAÇÕES QUILOMBOLAS E TRADICIONAIS/UFMG. Quilombo de Mangueiras, em Belo Horizonte, pode ser impactado pela Copa de 2014. UFMG, 2014. Disponível em: $<$ http://www.abant.org.br/conteudo/002PRINCIPAL/Nota_sobre_ Mangueiras.pdf $>$. Acesso em: 3 fev. 2018.

PARNELL, Susan; OLDFIELD, Sophie. The Routledge Handbook on Cities of the Global South. London: Routledge, 2014.

OLIVEIRA, Wallace. Comunidade de Mangueiras conquista o reconhecimento de suas terras. Brasil de Fato: uma visão popular do Brasil e do mundo, 9 fev. 2016. Disponível em: <https://www. brasildefato.com.br/node/34088/>. Acesso em: 1 fev. 2017.

QUIJANO, Aníbal. Colonialidad del poder y classificación social. Journal of World Systems Reasarch, v. 6, n. 2, p. 342-386, 2000.

RATTS, Alex. Eu sou atlântica: sobre a trajetória de vida de Beatriz Nascimento. São Paulo: Imprensa Oficial do Estado de São Paulo, 2006.

SANTOS, Boaventura. Para além do pensamento abissal. Novos estudos-CEBRAP, n.79, p.71-94, 2007a. Disponível em: <http:// www.scielo.br/scielo.php? script=sci_is suetoc\&pid=0101330020070003\&lng=en\&nrm=i>. Acesso em: 30 out. 2017.

SANTOS, Boaventura. Para uma sociologia das ausências e uma das emergências. Centro de Estudos Sociais, 2008b. Disponível em: $<$ http:// www.ces.uc.pt/bss/documentos/sociologia_das_ausencias.pdf $>$. Acesso em: 10 jan. 2017. 
SEDLMAYER-PINTO, Sabrina; GINZBURG, Jaime. Walter Benjamin: rastro, aura e história. Belo Horizonte: Editora UFMG, 2012.

SIMMEL, George. A Metrópole e a vida do espírito. In. FORTUNA, Carlos (Org.). Cidade, cultura e globalização. Oeiras: Celta, 1997.

UNITED NATIONS, Department of Economic and Social Affairs (Population Division). World Urbanization Prospects: The 2011 Revision. Nova Iorque: United Nation, 2013. 